\title{
Exploratory Perspective on the Operational Worth of Big Data Analytics in Public and Private Organizations
}

\author{
Robert T. Dauphin, PhD. \\ Associate Professor of Public Administration \\ Albany State University \\ 504 College Drive Albany \\ Georgia 31705
}

\begin{abstract}
Evolving academic and practitioner literature is the prototypical transition in perception of big data analytics that supports transition away from a technical role toward a strategic operational worth-creating role (Ezingeard, McFadzean, \&Birchall, 2005; Sherizen, 2003; Van Opstal, 2006).However, there are limited academic work on the operational worth of big dataanalytics. This exploratory perspective helps to fill that gap. This exploratory perspective is done to analyze the ways big data analytics creates organizational worth; the types of metrics used to demonstrate its worth; the extent of big data analytics operational alignment and areas that can impede alignment. Operational worth advantages are analyzed through measures of perceived knowledge and actual knowledge. The analysis also underscores the relationship between perceived and actual operational worth advantages, and organizations of various organizational sectors. The analysis revealed key items of operational worth and found that overall perceived assessment of advantages to be most prevalent over actual assessment of advantages. Conclusions revealed that leadership within organizations actually play a significant role in the success of big data analytics.
\end{abstract}

Keywords: Big-data, Analytics, Worth, Operational, Strategy, Predictive, Prescriptive, Descriptive

\section{Introduction}

The fast-evolving environment of big data analytics has activated the explosive use of electronic data among public and private sector organizations within the various levels of organizational operations. Global interconnectedness has made access to big data analytics unrestricted by time, geography, and distance. Insurrections and developments of big data analytics supplement and transform the attributes of the data (information)-intensive environment. The invasion of modernizations has hastened the bounds and gravity of adoption, thus intensifying demand and advancing society's reliance on big data.

The use of computers started the beginning of the paper-free era. Extensive embracing of mobile technology shifted wired computing to wireless. No longer restricted to just physical cable, data and information now permeate the air ways, an uncontainable medium. Universal computing has made the task of snatching data easier and the need increasingly compelling (Dourish, Grinter, Delgadode la Flor, \& Joseph, 2004; Graham \& Steinbart, 2006).

The saturation of big data analytics in our daily life has made government and private sector officials, technology specialists, policy analysts, and the general public more conscious of the advantages of big data insurrection and more conscious of the amount of information they can glean in less time (Berkowitz \& Hahn, 2003). The integration of Internet technology in the public and private sector management processes and operations as well as broadly publicized importance of big data analytics in organizational operations have brought big data analytics into organizational awareness. Rising awareness of the importance of data has placed big data analytics at the head of public and private organizations concerns (Allen, 2005; Ernst \& Young, 2007). Implementing big data analytics measures within organizations enhance and promote productivity, like collecting enough vital data (information) needed for organizational operations (Berkowitz \& Hahn, 2003).

The large-scale utilization of big data analytics has traditionally dependent on expertise and tradeoffs, that is, weighing resources against other considerations, for example, financial resources versus availability and expertise versus functionality. Different driving forces challenge the traditional view of the utilization of big data analytics as a technical necessity or a cost center. Cost center usually refers to as departments, functions, sections, or individual whose cost, overall or in part, reflects an accepted overhead of an operation in return for services provided to other parts of the organization (Perseus Publishing, 2003). 
The developing academic and organizational perspective emphasize the use of big data analytics as a worth creator (Ezingeard, McFadzean, \& Birchall, 2005) that supports and enables organizational operations (Amit \&Zott, 2001), achieves organizational operational objectives (Chinburg, Sharda, \& Weiser, 2002), incorporates the stability and survivability of needed services (Allen \& Sledge, 2002) and allows operational resiliency. The movement away from cost is also labelled as going from a preventative approach to an enabling approach (Ezingeard et al., 2005).

Practitioner-oriented literature addresses big data analytics as being complementary to strategic organizational planning, such as, meeting organizational operational goals and objectives (Garigue \& Stefaniu, 2003) to enhance organizational operations by utilizing big data. The main driver of big data analytics remains enhanced organizational productivity and profitability, such as, organizations' reputation, market valuations, operational continuity, and competitive advantage (Symantec, 2002).

Big data analytics has grown beyond just the use of technology, for its use requires both individuals and processes. Therefore, organizations can use big data analytics to provide valuable mechanisms that go beyond the gathering of pertinent organizational data. Its application now personifies tactical and strategic operational objectives. This writer embarked on this analytical work to evaluate the assertion that big data analytics is an enabler of strategic organization operational worth. This analysis focused on identifying perspectives and ways big data analytics can add operational worth to organizations, and whether these perspectives can apply to the different organizational sectors (Public and Private sectors).

\section{Statement of the Problem}

The overall impetus of this analysis is to provide an enhanced understanding of big data analytics as being a means for facilitating the attainment of strategic organizational operational goals. Diverse literature encompasses the process of enhancing readers understanding of the operational worth of big data analytics. Academic exploration on the operational worth of big data analytics is in a nascent stage. Although the delivery of organization operational worth is not widely discussed in big data analytics management literature (Melville, Kraemer, \& Gurbaxani, 2004), there is also a lack of solid analytical and empirical studies on operational worth contributions attributable to big data analytics. Researchers have done little to no analysis to analyze the perspectives and knowledge of the operational worth of big data analytics and how it applies to organizations or how those perspectives may differ from one organizational sector to another.

Thus, this analysis will help to contribute knowledge that will advance the understanding of big data analytics as a means for strategic worth creation in organizational processes and services. It will help provide perspectives of how individuals within organizations interpret the worth that big data can provide to their organization. Organizations can use the benchmark of worth to measure organizations use in positioning themselves to pursue new big data-enablers, worth creating operational opportunities in an increasingly networked functioning world. In an analysis of the apparent worth of big data, the incentive for analyzing perspectives resides on organizations demand of strategic operational worth from all their resources, thus, this writer will analyze emerging information technologies to a great degree to assess how individuals within organizations use worth to allocate resources (Subramanian and Nosek, 2001).

As the usage of big data analytics became less of a technological concern and more of an operational strategy, the need to connect big data and operational strategies became obvious to organizational managers (Huang \& Hu, 2007). This thought is also apparent in the literature on the connection of big data analytics strategy to organizational objectives (e.g., Birchall, Ezingeard, McFadzean, Howlin, \& Yoxall, 2004); nonetheless, there is insufficient academic work on how officials in organizations view the connection. Though metrics can offer direct understanding into the worth of big data analytics to organizations (Chew, Clay, Nash, Bartol, \& Brown, 200), the issue of quantifying big data analytics investment returns continues because there are no generally recognized methods to quantify the effect of big data analytics(Nichols \& Sudbury, 2006).

Furthermore, there is an absence of adequate scholarly works on the types of metrics sought out by organizational leaders. Thus, why should organizational leaders' have a working knowledge of big data analytics? What are the actual ways that big data analytics adds to the operational worth of organizations? What is the relationship, if any, between the overall perceived operational worth of big data analytics and organizations who do not rely on big data analytics? What metrics, if any, do organizational leaders use in the valuation of big data analytics? What role leadership should play regarding the alignment of their organizations' big data analytics strategy and operational strategy? What are the reasons for misalignment between big data analytics strategy and operational strategy? 


\section{Literature Review}

\section{Introduction}

Big dataanalytics is interdisciplinary in nature; studies in this area must vary among disciplines: public management, business management, information technology, management information systems, cryptography, policy, law, finance, economics and more. Due to comprehensive attention of big data analytics currently, this analysis focuses on a few noteworthy methods and trends considered vital to understanding big data analytics as an operational enabler. Among the main components identified as contributing to the operational perspective of big data analytics involve: the increasing sphere of big data analytics and its growing significance; the changing title-role of data within organizations; operational significance and its creation processes; big data analytics strategy alignment to operational strategy; and metrics for assessing and justifying big data analytics investments.

Consequently, the rapid advancement of complex big data analytics and escalating transactions conducted over the Internet are not corroding the importance of big data analytics. Big data analytics has been ever-increasing in scope and increasing in importance. The operational responsibilities of public and private managers can range from seeking strategies to enhance organizations operational worth to identify actual and potential client needs.

The concept of big data analytics is regarded as multi-faceted; its management goes further than technical and into organizational, structural, behavioral, and social aspects (Dhillon, 2004). Big data management now concern ethical and legal issues, such as spyware (Sipior, Ward, \& Roselli, 2005), and regulatory compliance, such as FISMA and HIPAA (Robinson, 2005). These illustrations of management complexity are indications of the substantial amount of material flaring up passions in this discipline.

There exists an increasing focus onbig data analytics management in articles and journals to reinforce organizational concerns. However, perspectives on organization operational worth of big data analytics remain a promising academic research area. Although research studies have been conducted to determine sources of worth creation, much of the research (e.g., Melville, Kraemer, \& Gurbaxani 2004) has been concentrated on worth creation in big data analytics, the broader discipline of big data analytics. Some of the variables discussed in these studies may be relevant to big data analytics. Despite the research gaps, organizational practitioners have expressed big data analytics as being integral to operational needs (e.g., Deloitte \& Touche, 2007).

Numerous components identified in this review appear to be shaping and strengthening the operational perspective of big data analytics. Key among these components are: the growing domain of big data analytics and its increasing significance; the changing role of big data analytics in organizations; operational value and its creation processes; aligning big data analytics strategy with operational strategy; metrics for assessing and justifying big data analytics investments, and;big data analytics as a maturing scholarly discipline.

\section{Growing Sphere of Big Data Analytics}

Articles and journals written on the core subject of big data analytics are inexhaustible because big data analytics has many spheres; common terms used to describe these spheres are: algorithm, analytics, descriptive analytics, predictive analytics, prescriptive analytics, batch processing, Cassandra, cloud computing, cluster computing, dark data, data lake, data mining, data scientist, distributed file system, ETL (Extract, Transform and Load), Hadoop, inmemory computing, IoT, machine learning, MapReduce, NoSQL, R, spark (Apache Spark), and stream processing. Most of these terminologies must be viewed in context of their use in big data analytics (Petersen, Larsen, Schou, \& Strickland, 2004).

\section{Structured v Unstructured Data:}

This is one of the varieties of Big Data. Structured data is basically anything than can be put into relational databases and organized in such a way that it relates to other data by tables. Unstructured data on the other hand involves everything that organizations cannot put into relational databases or organized in relation to other data, such as email messages, social media posts and recorded human speech etc. 


\section{Analytics:}

Involves making inferences and discussing large sets of data. There are three different types of analytics. They are;

\section{Descriptive Analytics:}

involves explaining transactions done in percentage terms such as, an organization spent $25 \%$ on binders, $35 \%$ on copy papers, $20 \%$ on staples and the rest on miscellaneous items the previous year using the organization's credit card. Descriptive analytics can also involve lots of other details.

\section{Predictive Analytics:}

In Big Data predictive analytics, data scientists may use advanced techniques like machine learning, and advanced statistical processes to forecast the weather, economic changes, etc. an illustration of predictive analytics involves an organization analyzing their spending history for the previous 5 years and observed a somewhat consistent spending pattern, the organization can safely forecast with high probability that next years will be similar to previous years. Thus, this is not about 'predicting the future' rather 'forecasting with probabilities' of what might happen.

\section{Prescriptive Analytics:}

Prescriptive analytics builds on predictive analytics by including 'actions' (i.e. fewer binders or copy papers or staples) and analyzing the resulting outcomes to 'prescribe' the best category to target to reduce an organization's overall spending. Using an organization's spending illustration, an organization may want to identify which spending to target (i.e. binders, copy papers, staples etc.) to make a huge impact on the organization's overall spending. Extending this logic to big data one can imagine how administrators and executives can make data-driven decisions by looking at the impacts of previous decisions in front of them.

\section{Data Scientist:}

Include experts who can make sense of big data by extracting raw data from 'data lake,' massage it, and develop insights. Some of the expert skills required for data scientists are analytics, statistics, computer science, creativity, storytelling and understand business context.

\section{Data lake:}

A Data Lake is a large repository of enterprise-wide data in raw format. Data lake makes it easy to access enterprisewide data organizations really need to know what organizations are trying to identify and how to process and make intelligent use of the data. However, Data warehouses is a similar concept as Data lake in that they entail repositories for enterprise-wide data, but in a structured format after cleaning and integrating other sources. Data warehouses are typically used for conventional data (but not exclusively).

\section{Algorithm:}

Involves using mathematical formula or the use of statistical process to perform data analyzes. Big Data analytics made the term 'algorithm' contemporary and more popular.

Distributed File System: Because big data is sometimes too large to store on a single system; Distributed File System is a data storage system use to store large volumes of data across multiple storage devices and it helps to decrease the cost and complexity of storing large amounts of data.

Cluster computing: It is a fancy expression for computing using a 'cluster' of pooled resources of multiple servers. Technically, it involves nodes, cluster management layer, load balancing, and parallel processing, etc.

Machine learning: Machine learning is a method of designing systems that can learn, adjust, and improve based on the data fed to them. Using predictive and statistical algorithms that are fed to these machines, they learn and continually zero in on "correct" behavior and insights and they keep improving as more data flows through the system.

ETL (Extract, Transform, and Load): Involves the process of extracting raw data, transforming them by cleaning or enriching the data for ideal use and uploading them into appropriate repository for system use. Even though originally from data warehouses, ETL processes are used while 'ingesting' i.e. taking or absorbing data from external sources in big data systems.

Hadoop: Hadoop symbolizes big data. It is an open source software framework that consists of what is described as Hadoop Distributed File System (HDFS) that allows for storage, retrieval, and analysis of very large data sets using 
distributed hardware. YARN (Yet Another Resource Scheduler) is a resource scheduler software piece. The Apache foundation, which came up with Hadoop, also came up with Pig, Hive, and Spark software pieces.

In-memory computing: In-memory computing is a technique to moving the working datasets entirely within a cluster's collective memory and avoid writing intermediate calculations to disk.

Generally, any computing that can be done without accessing I/O is expected to be faster. Apache Spark is an inmemory computing system that has huge advantage in speed over I/O bound systems like Hadoop's MapReduce.

Batch processing: Even though Batch data processing has been around since mainframe days, it gained additional significance with Big Data given the large data sets that it deals with. Batch data processing is an efficient way of processing high volumes of data where a group of transactions is collected over a specific period.

Cassandra is a popular open source database management system managed by The Apache Software Foundation. Apache can be credited with many big data technologies and Cassandra was designed to handle large volumes of data across distributed servers.

Data mining: Data mining involves finding meaningful patterns and deriving insights in large sets of data using sophisticated pattern recognition techniques. It is closely related to the term analytics in that data miners mine data to perform analytics. To glean meaningful patterns, data miners use statistics, machine learning algorithms and artificial intelligence.

IoT: IOT (Internet of Things) is the interconnection of computing devices in embedded objects (sensors, wearables, cars, fridges etc.) through the internet. They enable organizations to send and receive data. IOT generates large amounts of data and presents many big data analytics opportunities.

MapReduce: MapReduce is a programming model and it is best understood by noting that Map and Reduce are two separate items. In this programming system, model first breaks up big data dataset into pieces (in technical terms into 'tuples') so it can be distributed across different computers in different locations (cluster computing) which is essentially the Map aspect. Then the model collects the results and 'reduces' them into a single report. MapReduce's data processing model goes together with Hadoop's distributed file system.

NoSQL: NOSQL (Not ONLY SQL :-) is a database management system designed to handle large volumes of data that does not have a structure or what is technically known as 'schema' (like relational databases have). NoSQL databases are often well-suited for big data systems because of their flexibility and distributed-first architecture needed for large unstructured databases.

R: ' $R$ ' is a programming language that works very well with statistical computing. It is one of the most popular languages in data science.

Spark (Apache Spark): Apache Spark is a fast, in-memory data processing engine to efficiently execute streaming, machine learning or SQL workloads that require fast iterative access to datasets. Spark is generally a lot faster than MapReduce.

Stream processing: Stream processing is designed to act on real-time and streaming data with "continuous" queries. Combined with streaming analytics, it gives organizations and individuals the ability to continuously calculate mathematical and statistical analytics on the go within the stream. Stream processing solutions are designed to handle very high volume in real time.

Dark Data:Dark data is devised to scare organizations. It refers to data that is gathered and processed for meaningless purposes and thus, it is considered 'dark' and may never be analyzed. It could be social network feeds, call center logs, meeting notes and what have you. There are many estimates that anywhere from $60-90 \%$ of all organizations data may be 'dark data'.

Cloud computing: Cloud computing has become universal and may not be needed but was included for completeness. It is essentially a software and/or data hosted to run on remote servers and accessible from anywhere on the internet.

\section{Big Data Analytics Operational Worth}

The idea of big data analytics operational worth and its established processes is a subject of administrative and management articles that are gradually proliferating. Articles and journals coverage of big data analytics operational worth include contributions from several disciplines to include finance, management, information systems, economics, strategy, accounting, and operations research (Melville, Kraemer, Gurbaxani, 2004). 
Scholars can extrapolate from sources of operational worth creation from numerous studies, among which are Information Technology (IT) operational worth (Tallon, Kraemer, \& Gurbaxani, 2000), IT competitive advantage (Kearns \& Lederer, 2003), information systems worth (Cronk \& Fitzgerald, 1999), e-business worth (Amit \&Zott, 2001), and net-enabled operational worth (Barua, Konana, Whinston, \& Yin, 2004).

The idea of the establishment of operational worth within the domain of technology has kindled support for the establishment of operational worth of big data analytics. The operational worth of big data analytics has been established (Nolan, 1982) and that big data analytics has always been viewed as an asset or resource (Thompson and Kaarst-Brown, 2005). Therefore, big data analytics assets are accepted as organization operational-critical assets and adequately protecting such data is crucial to organizational operations (Information Technology Governance Institute, 2006).

Big data analytics operational worth has been addressed in terms of its advantages (Ezingeard et al., 2005). Wylder (2003) affirms that big data analytics has operational worth that is fundamental to organizations but suggests an even higher tier for big data analytics, as a strategic plan of an organization so that it is embedded in operational activities. Ezingeard et al. (2005) develop a four-layer model of organization operational advantages by asking high ranking officials what they expect to gain through big data analytics. Ezingeard et al. determine four categories of advantages to organizations:

1. Operational advantages are those with useful instantaneous influence on the ability to deliver services and products efficiently and effectively, to include; resilient operational processes, improved client service, better data usage, and enhanced responsiveness.

2. Tactical advantages are those with useful medium-term influence on relationships with transaction partners, to include; easy compliance; better control; better understanding of operational opportunities; and commitment from other organizations and clients.

3. Strategic advantages are long-term and connected with competitive advantage, to include; better governance, discounted equity i.e. greater confidence to providers and clients.

4. Organizational advantages are those highly regarded by the government or key actors, these include improve service value; competitive benefit; and sustainability of operation.

\section{Changing Responsibilities of Data Managers}

Among articles written on risk analysis, productivity assessments, operational continuity planning, and policies, scholars have promoted the importance of having data specialists become an active and influential part in the operation or assignment of their organization. Additionally, they suggested that data specialists become familiar with security services in ways that support organizational operational vision and objectives. A vital role of data specialists is to promote knowledge and influence that will improve the understanding of critical operational issues to high ranking organization officials. This standpoint is consistent with operational trends to create a managerial role for data specialists, namely the Chief Data Officer (CDO) and the broader role, Chief Operations Officer (COO). A common organizational title in public and private organizations (the financial services sector) is Chief Risk Officer (CRO) with responsibilities that involve risk management and preventive strategies to complement the functions of security. Big data analytics has become a significant contributor in organization operational strategies and decisionmaking processes (Johnson \& Spivey, 2008).

The transition of the position data specialist from a custodian responsibility to C-level manager would start a new occurrence with the creation of Chief Data Officer or CDO (Fitzgerald, 2007). The impetus would be to underscore the importance of big data analytics in public and private organizations and the necessity to bestow power and authority in the individual for effectiveness. Nevertheless, organizations would gradually except C-level data officers within their operational chain, instead of Director of Operations or Vice President of Operations as was in the past (Wylder, 2003). Chief Data Officer would become the new description for the position (Whitten, 2008).

The transformation of the role of big data analytics to organizational leadership role, would make it an equivalent to operational management, which changes its focus. The CDO would support operational objectives and is highly visible within organizations to maximize operational effectiveness (ASIS International, 2008; Garigue \& Stefaniu, 2003). The role is no longer considered a process-only role that deals only with technical operational measures (Allen, 2006) to keep organizational productive, to include: policies, practices, tools, and methods. Instead, the role would be one that aligns organizations operations and data strategies to insert the worth of big data to meet organizations objectives. 
In order to shift big data to a strategic position, it is necessary to integrate organizations operational perspective with the technical perspective (Allen, 2006). Soft skills, such as managing, communicating, and stressing the operational reasons for big data analytics objectives must supplement technical skills (Kim, Hsu, \& Stern, 2006).

\section{Aligning Big Data Analytics Strategy with Operational Strategy}

The alignment of organization operational strategy and big data analytics strategy within organizations can be approached in different ways and is well documented in the literature (Chan \& Reich, 2007b). Strategy alignment studies are often pursued at the Director level at which planning methodologies are selected and strategies established (Campbell, Kay, \& Avison, 2005). Studies have associated overall better organizational performance to strategic big data alignment (Chan, Huff, Barclay, \& Copeland, 1997). Alliance leads to the strategic utilization of IT (Chan, Sabherwal, \& Thatcher, 2006), competitive advantage (Kearns \& Lederer, 2003), and is vital to the quest for better value from big dataanalytics (Chan, Huff, Barclay, \& Copeland, 1997).

The vital achievement social dimensional alignment factor for aligning big data analytics with organization operational plans rest on communication between big data analytics specialists and organizations operational leaders (Luftman \& Brier, 1999). Sledgianowski, Luftman, and Reilly (2006) develop and validate a survey instrument to assess strategic alignment maturity in organizations. According to Sledgianowski, Luftman, and Reilly the measurement instrument is the first of its kind to associate the different aspects of organizational practices and strategic big data analytics choices that facilitate big data analytics and operational alignment.

Huang and $\mathrm{Hu}$ (2007) highlight four main elements necessary to accomplish sustainable alignment between big data analytics and organizational operations, they include: integrated big data analytics plan with operational plan, effective communication, establishment of strong relationships between data specialists and operations, and an organizational culture of alignment. Huang and Hu's case study reveal that these four elements are enhanced by the organization-wide implementation of an established strategic administrative managerial tool, the balanced scorecard. The implementation process of the balanced scorecard allows officials to communicate openly on the state of organizations' operations.

Thus, a simple practical framework established to align organizational investments and operational strategy is COBIT or Control Objectives for Information and related Technology (McCollum, 2006). The framework calls for organizational leaders, directors, and professionals to align their organizations systems with operational objectives, quality standards, monetary controls, and security needs (Dhillon \& Mishra, 2006).

\section{Growing Scholarly Discipline}

Big data analytics as a scholarly discipline is in its infancy stages (Kurose, 1999 as cited in Chinburg, Sharda, \& Weiser, 2002). Although a scarcity of research studies exists, new research on operational issues of big data analytics may evolve as big data analytics develops as a scholarly discipline (Hentea, Dhillon, \& Dhillon, 2006).

Scholars have and would support big data analytics programs in academic curricula and have and would advocate that big data analytics course content include organizations' operational aspects (Cegielski, 2008). Big data analytics curricula emphasizing operational perspectives can produce graduates with hybrid skills needed for administrative and management careers. Hence, the merging of multiple disciplines would provide new curricula necessary for development of cross-functional skill sets, such as those mandated for managerial success and organizational productivity (Walters, 2007)

\section{Discussion and Implications}

There is no one best way to conceptualize the operational worth of big data analytics, nor is there one best way to implement it. The operational worth of data analytics can be implemented by analyzing the characteristics of successful organizations. Exploration of leadership's knowledge of ways that big data analytics adds operational worth to organizations remains a vital component. The exploration must focus on how to effectively and efficiently structure organizations operations to enhance the operational worth of big data analytics. The consideration of leadership's knowledge and responsibilities will serve as a base to establish and implement big data analytics transformational change to enhance the operational worth of data analytics in organizations. Additionally, researching other organizations big data analytics operational worth processes rest on shared operational strategy and organizational values. Effective big data analytics operational strategies can be identified within any of these orientations. The question is not which orientation is correct, but rather which perspective (s) on big data analytics operational strategies are best suited to an organization's operational approach and fit best within the larger data 
analytics strategy of an organization. The ideal is to create some synergy between the purpose, the process, and the perceive big data analytics strategy of the organization. One can reasonably surmise that organizations can enhance their operational worth with increase data on client or investor confidence, preservation of organization assessment, and preserving organizational brand and reputation with data analytics.

\section{Conclusion}

The goal of this exploratory perspective was to highlight, identify, and assess the need for big data operational worth within organizations. During exploration, this writer observed that leadership within organizations can determine the manner big data analytics can create operational worth; determine the types of metrics used; and highlight areas of misalignment. These determinations are predicated on leadership's experience, knowledge, and skill on data analytics.

Hence, organizational leaders can identify whether certain big data analytics strategy advance their organization's operational strategy. Leadership should do a good job communicating the direction of their organization's operational worth to data analytics professionals, because there are inhibitors that one can attribute to weak data analytics strategy,

This exploratory perspective substantiates the opinion of big data analytics as a positive enabler that can enhance organizations' operational worth, by providing organizations information to increase client or investor confidence, preserving organizations valuation, and preserving brand strength. Big data analytics allows for better management of organizations' resources, highlighting education and training needs, and help enhance organizations intellectual property.

\section{References}

Abu-Salih, B., Chan, K.Y., Al-Kadi, O. (2020). Time-aware domain-based social influence prediction.

J Big Data Vol. 7, No. 10. Retrieved from https://doi.org/10.1186/s40537-020-0283-3

Allen, J. H., \& Westby, J. R. (2007). Characteristics of effective security governance. EDPACS, 35(5). Retrieved February 24, 2019, from ProQuest database.

Amaio, T. E. (2009). Exploring and examining the business value of informationsecurity: corporate executives' perceptions. Retrieved November 25, 2019, fromhttps://books.google.com

Amit, R., \&Zott, C. (2001). Value creation in e-business. Strategic Management

Journal, 22, 493-520. Retrieved October 8, 2019, from ProQuest database.

Ashton, R. H. (2005). Intellectual capital and value creation: A review. Journal of Accounting Literature, 24, 53-134.

Retrieved March 22, 2019, from ProQuest database.ASIS International. (2008). Chief security officer guideline.

Retrieved October 24, 2019, from http://www.asisonline.org/guidelines/guidelineschief.pdf

Bakhthemmat, A., Izadi, M. (2020). Decreasing the execution time of reducers by revising clustering based on the futuristic greedy approach.

J Big Data Vol. 7 No.6. Retrieved from https://doi.org/10.1186/s40537-019-0279-z

Barua, A., Konana, P., Whinston, A. B., \& Yin, F. (2004). An empirical investigation of net-enabled business value. MIS Quarterly, 28(4), 585-620. Retrieved August 30, 2019, from ProQuest database.

Berkowitz, B., \& Hahn, R. W. (2003). Cybersecurity: Who's watching the store? Issues in Science and Technology, 19(3), 55-62.

Retrieved November 2, 2019, from ProQuest database.

Campbell, B., Kay, R., \& Avison, D. (2005). Strategic alignment:

A practitioner's perspective. Journal of Enterprise Information Management, 18(6), 653-664. Retrieved March 13, 2016, from ProQuest database.

Cegielski, C. G. (2008). Toward the development of an interdisciplinary information assurance curriculum: Knowledge domains and skill sets required of information assuranceprofessionals. Decision Sciences Journal of Innovative Education, 6(1), 29-49. Retrieved May 20, 2019, from ProQuest database.

Chan, Y. E., Huff, S. L., Barclay, D. W., \& Copeland, D.G. (1997).

Business strategic orientation, information systems strategic orientation, and strategic alignment. Information Systems Research, 8(2), 125-150.

Retrieved June 20, 2019, from EBSCOhost database.Chew, E., Swanson, M., Stine, K., Bartol, N., Brown, A., \& Robinson, W. (2008, July). Performance measurement guide for information security (NIST Special Publication 800-55 Revision 1). Retrieved August 7, 2019, from

National Institute of Standards and Technology via Computer Security ResourceCenter: http://www.csrc.nist.gov/ 
Chinburg, S. J., Sharda, R. \& Weiser, M. (2002). Establishing the business value of network security using the analytical hierarchy process. In N. Shin (Ed.), Creating business value with information technology: Challenges and solutions (pp. 203-219). Hershey, PA: Idea Group Publishing

Cronk, M. C., \& Fitzgerald, E. P. (1999). Understanding "IS business value": Derivations of dimensions. JITTA: Logistics Information Management, 12(1/2). Retrieved August 15, 2019, from ProQuest Telecommunications database.

Deloitte \&Touche. (2007). 2007 Global security survey. Deloitte \&Touche, LLP.

Retrieved May 21, 2019, from http://www.deloitte.com/dtt/research//0,1002,sid=1013\&cid=170582,00.html

Dhillon, G. (2004). Realizing benefits of an information security program. Business Process Management Journal, 10(3), 260-261. Retrieved August 15, 2019, from ProQuest database.

Dontha, R. (2017). 25 big data terms everyone should know. Dataconomy. Retrieved December 30, 2019 from https://dataconomy.com/2017/02/25-big-data-terms/

Dourish, P., Grinter, R. E., Delgado de la Flor, J., \& Joseph, M. (2004). Security in the wild: User strategies for managing security as an everyday, practical problem. Personal and Ubiquitous Computing, 8(6), 391-401.

Retrieved November 2, 2019, from ProQuest database.Ezingeard, J. -N., McFadzean, E., \& Birchall, D. (2005). A model of informationassurance benefits. Information Systems Management, 22(2), 20-29. Retrieved August 9, 2019, from ProQuest database.

Ezingeard, J. -N., McFadzean, E., \& Birchall, D. (2007). Mastering the art of corroboration: A conceptual analysis of information assurance and corporate strategy alignment. Journal of Enterprise Information Management, 20(1), 96-118.

Retrieved March 20, 2019, from ProQuest database.Faroukhi, A.Z., El Alaoui, I., Gahi, Y. (2020).Big data monetization throughout Big Data Value

Chain: a comprehensive review. J Big Data Vol. 7 No. 3. Retrieved fromhttps://doi.org/10.1186/s40537-019-028

Garigue, R., \&Stefaniu, M. (2003). Information security governance reporting.Information Systems Security, 4(12), 36-40. Retrieved March 8, 2019, from EBSCOhost database.

Hentea, M., Dhillon, H. S., \& Dhillon, M. (2006). Towards changes in information security education. Journal of Information Technology Education, 5, 221-233. Retrieved March 12, 2019, from EBSCO host.

Huang, C. D., \& Hu, Q. (2007). Achieving IT-business strategic alignment via enterprise-wide implementation o balanced scorecards. Information Systems Management, 24, 173-184. Retrieved April 25, 2019, from EBSCO host database.

Huang, S., Lee, C., \& Kao, A. (2006). Balancing performance measures for information security management: A balance scorecard framework. Industrial Management \& Data Systems, 106(2), 242-255. Retrieved January 20, 2016, from ProQuest database.

Huang, X., Radkowski, P., \& Roman, P. (2007). Computer crimes. The American Criminal Law Review, 44(2), 285335. Retrieved April 25, 2019, from ProQuest database.

International Organization for Standardization. (2007). Information technology -security techniques - information security management measurements(Publication No. ISO/IEC FCD 27004).

Retrieved on May 8, 2019, from http://www.iso.org/

Johnson, M. P., \& Spivey, J. M. (2008). ERM and the security profession. Risk Management, 55(1), 30-35. Retrieved May 24, 2019, from ProQuest database.

Kim, Y., Hsu, J., \& Stern, M. (2006). An update on the IS/IT skills gap. Journal of Information Systems Education, 17(4), 395-402. Retrieved March 25, 2016, from EBSCOhost database.

Luftman, J. N., Papp, R., \& Brier, T. (1999). Enablers and inhibitors of business-ISalignment. Communications of the Association for Information Systems, 1(11), 1-33. Retrieved June 9, 2019, from http://cais.aisnet.org/home.asp

McCollum, T. (2006). Bridging the great divide. Internal Auditor, 63(1), 49-53.

Retrieved June 22, 2019, from ProQuest database. McDaniel, G. (1994). IBM dictionary of computing. NewYork: McGraw-Hill.Melville, N., Kraemer, K., \&Gurbaxani, V. (2004). Review: Information technology and organizational performance: an integrative model of IT business value. MIS Quarterly, 28(2), 283-322. Retrieved March 16, 2019, from ProQuest database.

Robinson, T. (2005). Data security in the age of compliance. NetWorker, 9(3), 25-30.Retrieved November 1, 2019, from ProQuest database.

Rizk, A., Elragal, A. (2020). Data science: developing theoretical contributions in information systems via text analytics. J Big Data Vol. 7 No.7. Retrieved from https://doi.org/10.1186/s40537-019-0280-6

Sarno, R., Sinaga, F. \&Sungkono, K.R. (2020). Anomaly detection in business processes using process mining and fuzzy association rule learning. J Big Data7, 5. Retrieved fromhttps://doi.org/10.1186/s40537-019-0277-1 
Sledgianowski, D., Luftman, J. N., \& Reilly, R. R. (2006). Development and validation of an instrument to measure maturity of IT business strategic alignment mechanisms. Information Resources Management Journal, 19(3), 18-33.

Retrieved June 9, 2019, from ProQuest database.

Sussland, W. A. (2004). Business value and corporate governance: A new approach. Journal of Business Strategy, 25(1), 49-56.

Retrieved September 1, 2019, from ProQuest database.

Symantec. (2002). The value of information security. Retrieved August 27, 2019, from http://www.softchoice.com/portal/symantec/pdf/whitepaper_value.pdf

Tallon, P. P., \& Kraemer, K. L. (2007). Fact or fiction? A sense making perspective onthe reality behind executives' perceptions of IT business value. Journal of Management Information Systems, 24(1), 13-54. Retrieved October 12, 2019, from EBSCO database.

Teh, H.Y., Kempa-Liehr, A.W. \& Wang, K.I. (2020). Sensor data quality: a systematic review.

J Big Data Vol. 7 No 11. Retrieved from https://doi.org/10.1186/s40537-020-0285-1

Thompson, E. D., \&Kaarst-Brown, M. L. (2005). Sensitive information: A review and research agenda. Journal of the American Society for InformationScience and Technology, 56(3), 245-257. Retrieved March 25, 2019, from ProQuest database. 